\title{
Auricular Therapy for Treating Phantom Limb Pain Accompanied by Jumping Residual Limb: A Short Review and Case Study
}

\author{
Hongfang Tian · Hantong $\mathrm{Hu} \cdot$ Xingling Li $\cdot$ Jing Liu • \\ Qin Guo · Yang Li · Dexiong Han
}

Received: August 5, 2020 / Accepted: January 15, 2021 / Published online: March 4, 2021

(C) The Author(s) 2021

\section{ABSTRACT}

Phantom limb pain (PLP) is a common complaint among patients after amputation, while jumping residual limb is a rare post-amputation complication, they rarely happen at the same time and both remain difficult to manage. At present, there is a paucity of literature on this topic, and no treatment has been proven effective for treating both of them. In the present brief report, we described a patient who developed severe PLP accompanied by jumping residual limb after below-the-knee amputation and she was treated by auricular therapy (AT) with satisfactory effect.

Keywords: Auricular therapy (AT); Involuntary movements; Jumping residual limb; Movement disorders; Phantom limb pain (PLP)

H. Tian · H. Hu - X. Li · J. Liu - Q. Guo - Y. Li

D. Han $(\bowtie)$

Department of Acupuncture and Moxibustion, Third Affiliated Hospital of Zhejiang Chinese Medical University, Hangzhou City, Zhejiang Province, China

e-mail: han_0213@163.com

\section{Key Summary Points}

Why carry out this study?

Phantom limb pain (PLP) is a common complaint among patients after amputation, while jumping residual limb is a rare post-amputation complicationthey rarely happen at the same time and both are difficult to manage.

The aim of this article is to describe a successful auricular therapy (AT) treatment of severe PLP accompanied by jumping residual limb in a 28 -year-old female after below-the-knee amputation.

\section{What was learned from the study?}

After a 3-week period AT treatment, the intensity of pain, the frequency of jumping stump attacks, and the dosage of analgesic were significantly reduced, meanwhile, the overall condition of the patient was improved.

This case report demonstrates that AT may be an effective alternative therapy for PLP accompanied by jumping residual limb.

We believe that this is the first report of AT for treating PLP accompanied by jumping residual limb. 


\section{DIGITAL FEATURES}

This article is published with digital features, including a summary slide and video, to facilitate understanding of the article. To view digital features for this article go to https://doi.org/10. 6084/m9.figshare.13574603.

\section{INTRODUCTION}

Phantom limb pain (PLP) is defined as persistent painful sensations perceived in the missing portion of the amputated limb [1]. It is a common complication and the prevalence may be as high as $75-80 \%$ in amputees [2, 3]. Most of the amputees suffer from burning, cramping, pinprick, stabbing, itching, or other sensations of pain in the first few weeks following amputation. The onset of pain may be elicited by environmental, emotional, or physical changes. Although the frequency and intensity of pain diminish over time in most PLP patients, severe pain can persist in about $5-10 \%$ of amputees [4], affecting individuals' subjective well-being, as well as both physical and mental components of quality of life [5]. Regarding etiology and pathogenesis, PLP is regarded as one kind of neuropathic pain and is caused by a lesion of the somatosensory nervous system. At present, given to a lack of robust evidence to support the efficacy of many treatments, it remains difficult to effectively manage.

On the other hand, movement disorders following amputation is a rare complication and can manifest as the jumping residual limb phenomenon, the nature of which is a form of peripheral myoclonus and is characterized by sudden, brief, and sometimes repetitive muscle contractions, jerking, tremulousness or spasms of the residual limb [6]. Although it is reported that only $1 \%$ or less of these post-amputation patients experience spontaneous, involuntary, autonomous movements of the residual limb [7], it is significantly disturbing to patients when it does occur. The "jumping residual limb" syndrome is generally regarded as a form of spinal reflex myoclonus limited to the amputation site. Similarly, the pathophysiology has not been completely elucidated and there are currently no guidelines or standardized treatment for it.

In clinical settings, PLP and jumping residual limb rarely occur at the same time. Hence, we presented a case of a 28-year-old female suffering from phantom pain accompanied by intermittent myoclonus in her residual limb after amputation. Due to failure to respond to oral medication, we attempted the use of auricular therapy (AT) and achieved satisfactory symptom improvement in this patient.

\section{Pathogenesis of PLP}

The underlying mechanisms of PLP have commonly been classified according to the level of the nervous system: peripheral or central. On the one hand, peripheral mechanisms include mechanical stimulation, circulating catecholamines, proinflammatory immune factors, and other sensitive neurochemicals activating the residual limb neuromas [8]. On the other hand, the neural mechanism of PLP is closely related to the brain reorganization after denervation in the sensorimotor system [9]. The sudden absence of afferent nerves following amputation resulted in many changes at the peripheral and spinal levels. It is speculated that the changes of sensory field and cortical reorganization observed after amputation are related to PLP. This may explain why a number of amputees relieve PLP by rubbing their entire limbs, thus stimulating normal afferent inputs at cortical, spinal, and peripheral levels.

As an intractable condition, PLP has been studied by many researchers. As described above, although several hypotheses have been put forward, the accurate mechanisms underlying PLP remain inconclusive. Further in-depth research is warranted.

\section{Treatment of PLP}

Currently, PLP remains intractable to be managed. Conventional treatments include pharmacotherapy, surgical intervention, and adjunctive therapy.

Regarding pharmacotherapy, there are a variety of medications to choose from, which 
include tricyclic antidepressants, opioids, and nonsteroidal anti-inflammatory drugs (NSAIDs), etc. The most commonly used first-line medication is gabapentin, but a systematic review found that it is only beneficial for short-term analgesic efficacy. Tricyclic antidepressants are also commonly used, however, its role against PLP is not definitive [10] and it has been shown to fail to effectively control the pain $[11,12]$. Acetaminophen and NSAIDs are also prevailingly used for PLP [13]. Opioids (levorphanol, oxycodone, methadone, and morphine) provide analgesia without causing the loss of proprioception, touch, or consciousness by binding to peripheral and central opioid receptors. Calcitonin can also be used for PLP, but its therapeutic effect is mixed and the mechanism is unclear [14, 15].

Regarding surgical intervention, nerve resection, nerve root cutting, and anterior column cutting are gradually replaced by interventional surgery because of their large trauma and various complications. As a surgical technique, targeted muscle reinnervation (TMR) refers to transferring the residual peripheral nerve to the redundant motor nerve of target muscle, restoring physiological continuity, encouraging organized nerve regeneration, so as to reduce and potentially prevent nerve confusion and directional growth [16] and it presents a surgical solution to this problem as either a primary or secondary intervention [17]. Imageguided percutaneous nerve cryoablation is feasible and safe and may represent a new efficacious therapeutic option for patients with PLP [18]. Brain and spinal nerve stimulation therapy includes invasive intervention of deep brain stimulation (DBS), spinal cord stimulation (SCS), motor cortex stimulation (MCS), and dorsal root ganglion (DRG) stimulation. For those with chronic PLP, transcranial direct current stimulation (tDCS) and noninvasive interventions repetitive transcranial magnetic stimulation (rTMS) are targeted choice. However, current studies on the efficacy and safety of nerve stimulation therapy have not provided reliable results.

Regarding adjunctive therapy, it includes mirror therapy (MT), transcutaneous nerve stimulation, electroconvulsive therapy, biofeedback, acupuncture, massage, and so on [19]. MT was first reported in 1996, which helped to reduce PLP by eliminating the separation of visual proprioception in the brain [20]. One randomized study [21] also demonstrated its effectiveness and showed that the pain relief associated with MT may be due to the activation of mirror neurons in the hemisphere of the brain contralateral to the amputated limb. Local anesthetics can block peripheral nerves, plexi, dorsal roots, as well as the sympathetic nervous system, however, the effects are usually shortlived. Although longer-lasting blocks may increase the duration of anesthesia, they have the risk of irreversible functional impairment. Long-term epidural administration, such as steroids, midazolam, clonidine and opioids, usually results in serious side effects. Selective nerve root injection of ozone is a safe and effective new approach for the treatment of PLP [22]. Eye movement desensitization and reprocessing (EMDR) therapy is believed to reduce PLP through emotional processing of "painful memories", which are proposed to maintain PLP [23]. The results show that acupuncture is also beneficial to PLP [24-27]. Acupuncture stimulation in the artificial hand has an enhanced sensory feedback mechanism, which may be a new approach for PLP [28].

Over the past five decades, researchers have explored how PLP might be treated via medication, surgery, and various other approaches [8]. Nevertheless, there is still little high-quality evidence available for PLP treatments and most clinical trials are unconvincing.

\section{Pathogenesis of Jumping Residual Limb}

The jerking of the residual limb is generally associated with severe residual limb pain and can occur at variable periods after amputation. Sometimes it occurs in the immediate postoperative period and persists over weeks to months, but they may also develop gradually after a variable latent period and persist indefinitely. Jumping residual limb is usually precipitated by voluntary movement, but can also be triggered by cutaneous stimuli. At present, the pathophysiology of "jumping residual limb" is 
still unclear. The latest research has shown that "jumping residual limb" represented a clinical entity in a series of dyskinesia, which was related to peripheral nerve injury or more common peripheral-induced dyskinesia. Peripheral trauma caused by amputation is likely to alter sensory input and induce central cortical and subcortical reorganization, resulting in dyskinesia $[29,30]$. During amputation, nerve damage is inevitable. They amplify or distort natural signals and provide exaggerated input to the central nervous system [12]. Some researchers suggest that the neural anatomical network connecting the somatic and sympathetic nervous systems and participating in substance $P$ directly initiates the abnormal depolarization of anterior horn cells. Myoclonus is caused by the transient activation of a muscle, resulting in convulsions in the affected area. This activation may arise from the cortex, subcortical structure, spinal cord, or nerve root and plexus [31-33]. Although some progress has been made in the investigation of its mechanism, jumping residual limb still needs to be further researched.

\section{Treatment of Jumping Residual Limb}

The mechanism underlying jumping residual limb is still unclear, nevertheless, several treatment methods have been applied to treat it, such as gabapentin, pramipexole, benzodiazepine, injection of botulinum toxin, and phenol [6, 33-39]. However, current available literature on treating jumping residual limb is all case reports, and there are no strict randomized controlled trials to support their effectiveness. Because of the rarity of jumping residual limb phenomenon and the complexity of its pathogenesis, to date, no consensus-based best practice is recommended.

\section{The Relationship Between PLP and Jumping Residual Limb}

Typically, but not in all cases, patients with jumping residual limb experience associated neuropathic pain, and phantom or residual limb pain. According to the literature research, rare patients present jumping residual limb and
PLP simultaneously. A close relationship between pain and the movement disorder could lead to the theory that pain might be a specific trigger for obsequent development and persistence of involuntary movements following peripheral injury [32]. Yet, there is no sufficient evidence to prove that one treatment is effective to treat PLP accompanied by jumping residual limb.

\section{Cases of PLP Accompanied by Jumping Residual Limb from the literature}

Jumping residual limb is an uncommon clinical phenomenon, especially in those accompanied by PLP. There is a paucity of published literature about it, only several available case reports on this topic focused on the intractability in treating both of them simultaneously, which are summarized in Table 1.

\section{Compliance with Ethics Guidelines}

Written informed consent was obtained from the patient for publication of this case report and any accompanying images. Institutional review board approval is not required for a case report.

\section{CASE PRESENTATION}

A 28-year-old female patient was admitted to the Acupuncture Ward of the Third Affiliated Hospital of Zhejiang Chinese Medical University in December, 2019, due to severe PLP accompanied by jumping residual limb. Her medical history was as follows. She had undergone a below-the-knee amputation of the right leg due to a severe carbon fire burn in November 2019. After amputation, she began to suffer from persistent unbearable severe PLP, which attacked as a knife cutting her leg and the most severe pain site was located in her phantom foot, accompanied by intermittent involuntary movements of the residual limb (typical onset of symptoms was displayed in Supplemental Video 1). 


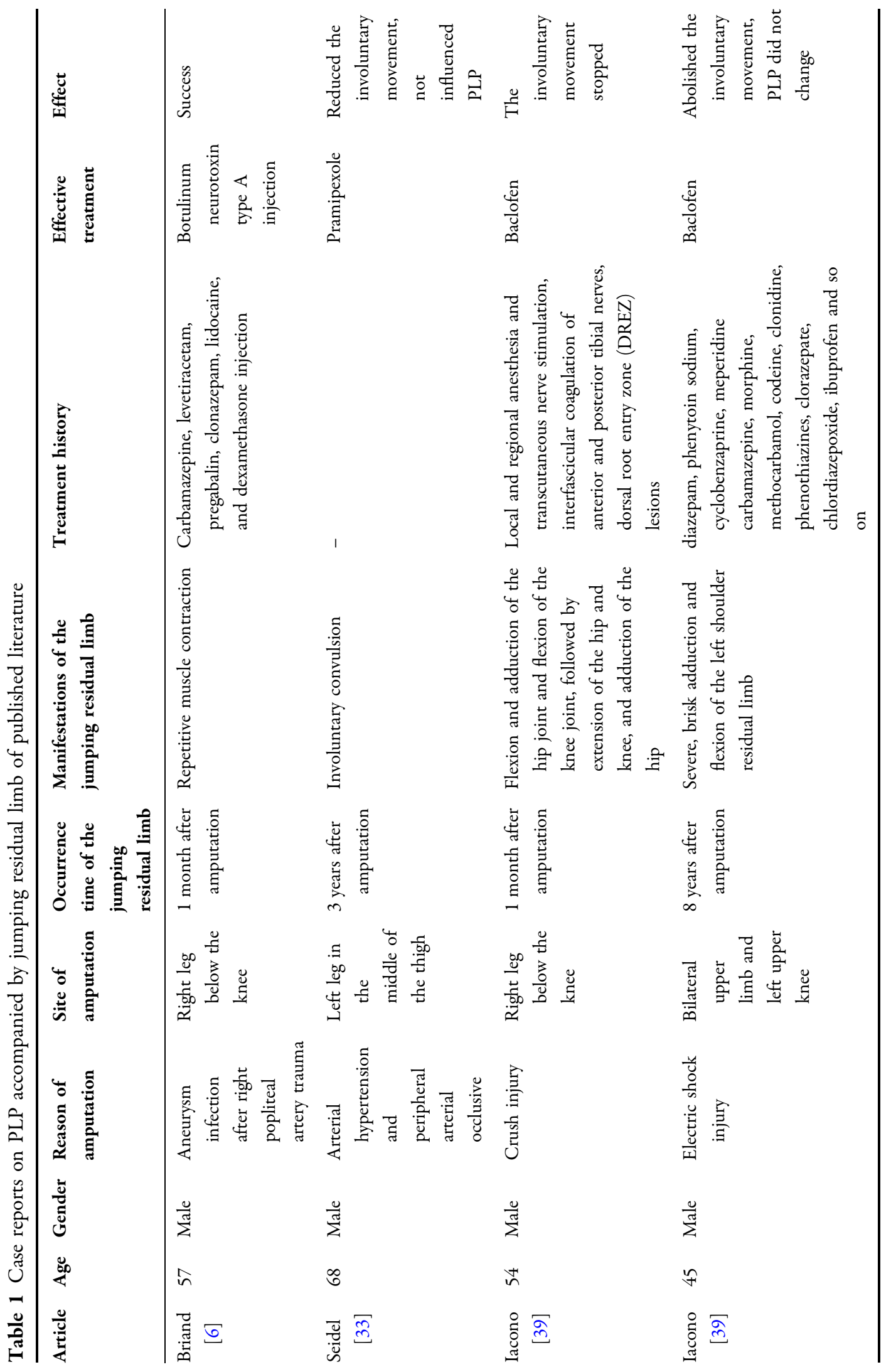



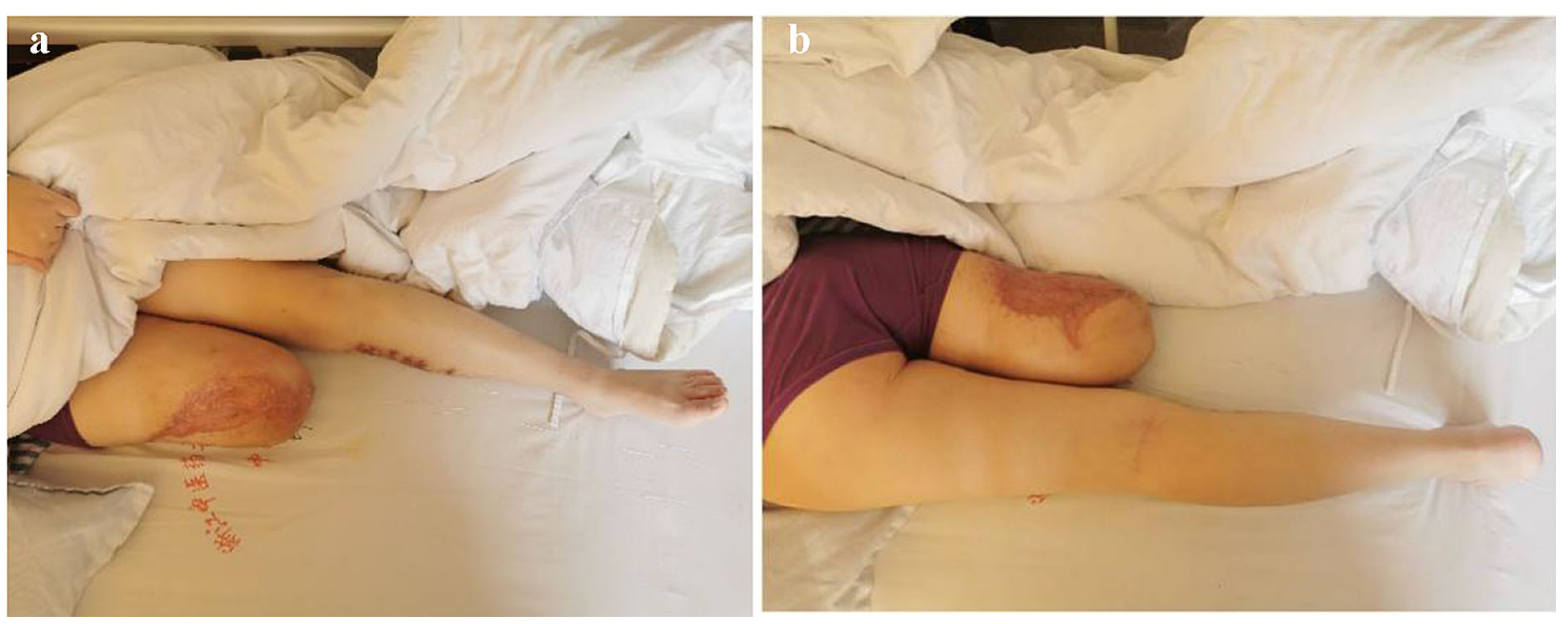

Fig. 1 a The patient's condition after amputation (front view). b The patient's condition after amputation (back view)

The pain was usually aggravated at night, without sweat or palpitation. These movements attacked about 13-15 times a day, which lasted from minutes to hours and always worsen the PLP. They were aggravated by action at daytime and usually disappeared during sleep. The pain was so severe that it seriously affected her sleep, the jumping residual limb brought her a lot of inconvenience and discomfort, and psychiatric scale assessment showed very high levels of anxiety and depression (Table 3).

On physical examinations at admission, the scar of the amputation was fully healed and freed from major adhesions (Fig. 1a and b). Hyperpathia was detected in the right leg. Patches of hyperalgesia were measured at the tip of the residual limb. Apart from involuntary, rapid, rhythmic myoclonic jerks of the residual limb, the neurologic examination showed no abnormalities. The results of routine biochemical and hematologic studies were normal. At present, the effect of pharmacological treatment of gabapentin tablets $(0.9 \mathrm{~g}$ bid plus $0.6 \mathrm{~g}$ qn), duloxetine hydrochloride capsules $(60 \mathrm{mg}$ bid) was unsuccessful and she had to inject tramadol (100 mg qn) to relieve pain. In addition, she took olanzapine tablets (5 mg qn) for sleep. Given that pharmacological medication could not control her disturbing symptoms, she decided to receive acupuncture as a complementary therapy.

\section{At Treatment Regimen}

On the basis of routine oral administration of gabapentin tablets and duloxetine hydrochloride capsules, she was treated with AT using magnetic beads on both ears. The selected points were heel (AH1), toe (AH2), ankle (AH3), knee (AH4), hip (AH5), lumbosacral vertebrae (AH9), Shenmen (TF4) and tender points (the locations of these auricular points are illustrated in Table 2 and Fig. 2a and b. AT was performed by an experienced acupuncturist. Before AT treatment, the acupuncturist disinfected the ears with $75 \%$ alcohol cotton ball and pasted magnetic beads on the above auricular points. The acupuncturist pressed against the points with the index finger and the thumb to the extent that the patient could bear the strength and feel distended pain or heat sensation. Each auricular point was pressed constantly for about $30-60 \mathrm{~s}$, and kept pressing for about $5 \mathrm{~min}$. During the retention period, the patient was informed to press these auricular points by herself 5-6 times a day, with 5 min every time, and change the magnetic beads every other day. The frequency of AT treatment was once in 2 days for a total of 3 weeks.

\section{OUTCOME MEASURES}

Primary outcomes included the change in dosage of previous medication, change in pain 

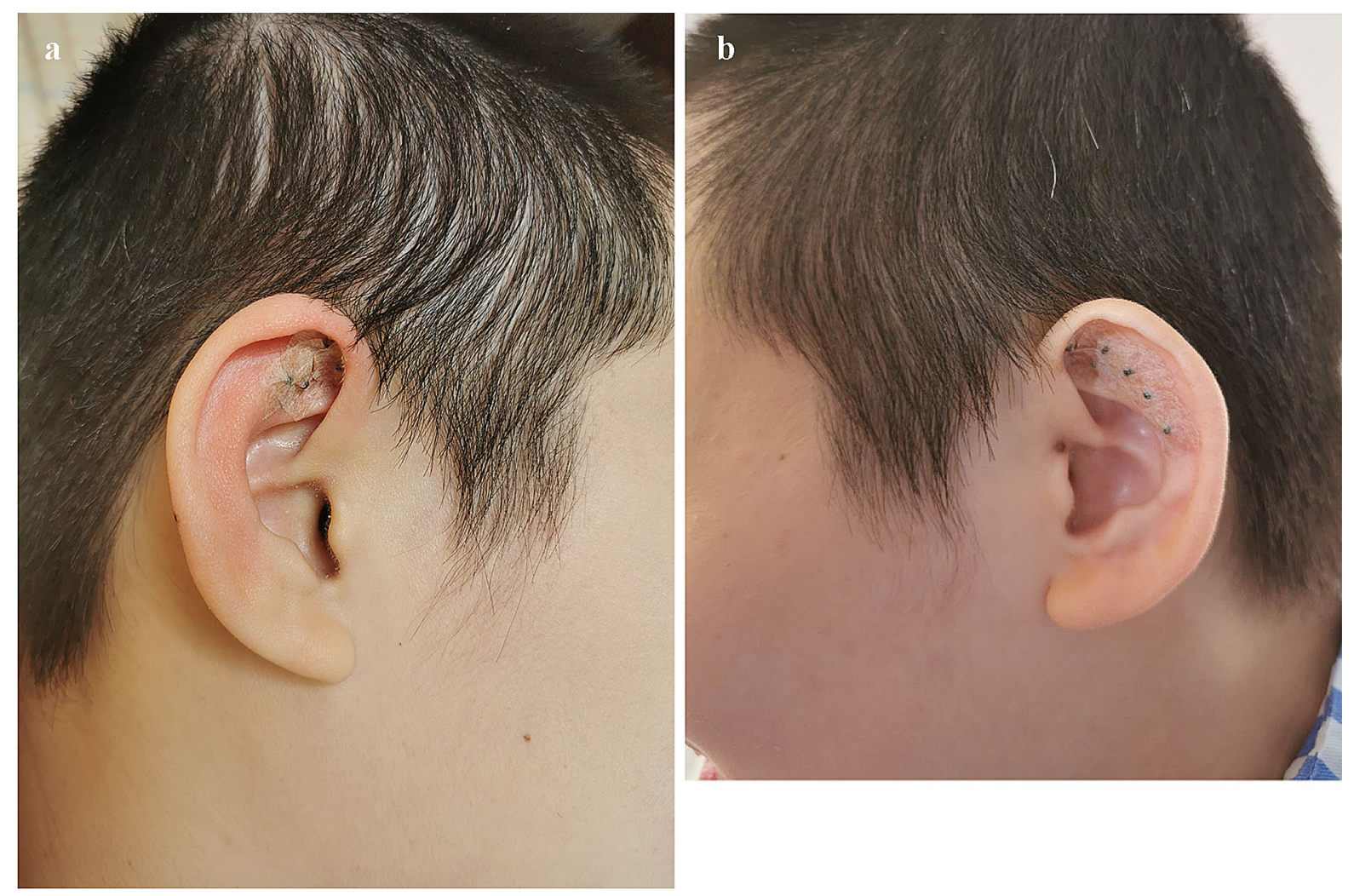

Fig. 2 a The selected points on the right ear. b The selected points on the left ear

intensity of PLP assessed by Visual Analogue Scale (VAS), and change in frequency of attacks of jumping residual limb. Secondly outcomes included the level of emotional state measured by Hamilton Anxiety Scale (HAMA) and Hamilton Depression Scale (HAMD) (Table 3).

\section{DISCUSSION}

Both PLP and jumping residual limb are difficult to manage, when they occur at the same time and interact with each other-the difficulty is more than doubled. According to comprehensive literature reviews, most of the available treatments in published literature are effective in dealing with either PLP or jumping residual limb, to date, rare treatment modality has been indicated to be effective in treating both of them simultaneously. Fortunately, we used AT to treat them and received satisfactory effect.

As a major part of acupuncture, AT is defined as "a health care modality whereby the external surface of the ear, or auricle, is stimulated to alleviate pathological conditions in other parts of the body". AT involves the relationships among the ear, energy lines (i.e., channels and meridians), and muscle regions comprising the whole body, according to the theory of somatic reflexology. This theory regards that when specific symptoms or diseases arise, it is projected onto the ear at a regular and measurable zone [40]. For instance, the auricular acupoints may manifest not only a decrease in auricular cutaneous electrical resistance but also a decrease in pain threshold [41]. Typical types of AT include auricular acupuncture (AA), electroacupuncture stimulation (EAS), and acupressure (AP), etc. AT has been used to treat a variety of disorders, including both psychological and somatic diseases. Because of its safety and effectiveness, as well as negligible side effects, it is receiving increasing acceptance by physicians and patients. Up till now, a great number of modern studies have indicated that AT is an effective therapy in the management of various types of painful conditions [42-49]. 
Table 2 The location of the auricular points used in the patient

\begin{tabular}{|c|c|}
\hline Auricular point & Location \\
\hline Gen (AH1) heel & $\begin{array}{l}\text { In the anteriosuperior part of the } \\
\text { superior antihelix crus at area } 1 \\
\text { of the antihelix }\end{array}$ \\
\hline Zhi (AH2) toe & $\begin{array}{l}\text { In the posteriosuperior part of } \\
\text { the superior antihelix crus, } \\
\text { inferior to the apex, at area } 2 \text { of } \\
\text { the antihelix }\end{array}$ \\
\hline Huai (AH3) ankle & $\begin{array}{l}\text { Inferior to } \mathrm{AH} 1 \text { and } \mathrm{AH} 2 \text {, at } \\
\text { area } 3 \text { of the antihelix }\end{array}$ \\
\hline Xi (AH4) knee & $\begin{array}{l}\text { On the middle } 1 / 3 \text { of the } \\
\text { superior antihelix crus, at area } \\
4 \text { of the antihelix }\end{array}$ \\
\hline Kuan (AH5) hip & $\begin{array}{l}\text { At the lower } 1 / 3 \text { of the superior } \\
\text { antihelix crus, at area } 5 \text { of the } \\
\text { antihelix }\end{array}$ \\
\hline $\begin{array}{l}\text { Yaodizhui (AH9) } \\
\text { lumbosacral } \\
\text { vertebrae }\end{array}$ & $\begin{array}{l}\text { Posterior to AH8 at area } 9 \text { of the } \\
\text { antihelix }\end{array}$ \\
\hline Shenmen (TF4) & $\begin{array}{l}\text { At the upper part of the posterior } \\
1 / 3 \text { of the triangular fossa, at } \\
\text { area } 3 \text { of the triangular fossa }\end{array}$ \\
\hline
\end{tabular}

Nevertheless, the exact mechanisms underlying AT for treating pain remain inconclusive. Based on existing literature, AA can restrain the descending pain pathway via activating the descending pain inhibitory pathway along the dorsal side of the spinal cord, so as to exert analgesic effects [50].

Besides, stimulations of auricular acupoints could promote the release of endorphin and enkephalin. Moreover, the neurophysiological connections between auricular acupoints and the human central nervous system (CNS) have been corroborated by functional magnetic resonance imaging (fMRI) [51]. Therefore, the analgesic effect of AT on this patient might be explained by these potential mechanisms, yet more rigorous experiment is required to confirm it.

In our case, although the PLP and jumping residual limb did not completely disappear, the intensity of pain was significantly reduced, the frequency of jumping residual limb attacks was markedly lessened, the dosage of analgesic was significantly reduced and the overall condition of the patient was improved significantly after a 3-week period treatment. After cessation of AT therapy, the symptoms of PLP were not worsened, instead, the oral medicine further reduced and the jumping residual limb rarely reemerged. This case report demonstrates that AT may be an effective alternative treatment for PLP accompanied by jumping residual limb.

Table 3 Timeline of drug administration, VAS score, frequency of jumping residual limb attacks, HAMA and HAMD scores

\begin{tabular}{llllllll}
\hline Date & $\begin{array}{l}\text { Gabapentin } \\
(\mathbf{g})\end{array}$ & $\begin{array}{l}\text { duloxetine } \\
\text { hydrochloride }(\mathbf{m g})\end{array}$ & $\begin{array}{l}\text { Tramadol } \\
(\mathbf{m g})\end{array}$ & $\begin{array}{l}\text { VAS } \\
\text { score }\end{array}$ & $\begin{array}{l}\text { frequency of } \\
\text { attacks (times) }\end{array}$ & $\begin{array}{l}\text { HAMA } \\
\text { score }\end{array}$ & $\begin{array}{l}\text { HAMD } \\
\text { score }\end{array}$ \\
\hline $\begin{array}{l}\text { Before } \\
\text { treatment }\end{array}$ & $\begin{array}{l}0.9 \\
\text { bid }+0.6 \\
\text { qn }\end{array}$ & $60 \mathrm{bid}$ & $100 \mathrm{qn}$ & 9 & $13-15$ & 30 & 32 \\
& & & & & & \\
1st week & $0.6 \mathrm{tid}$ & $60 \mathrm{bid}$ & $50 \mathrm{qn}$ & 8 & $9-12$ & 23 & 27 \\
2nd week & $0.6 \mathrm{tid}$ & $60 \mathrm{qd}+30 \mathrm{qn}$ & $50 \mathrm{qon}$ & 6 & $6-7$ & 19 & 23 \\
3rd week & $0.6 \mathrm{tid}$ & $30 \mathrm{bid}$ & - & 4 & $3-4$ & 13 & 16 \\
\hline
\end{tabular}




\section{CONCLUSIONS}

In summary, we presented a rare case report of PLP accompanied by jumping residual limb and AT was applied to improve the patient's symptoms significantly. Given that there is a lack of robust evidence to support the efficacy of many conventional treatments, AT may be an alternative therapy for treating PLP accompanied by jumping residual limb. Nevertheless, further studies with large samples are needed to investigate its efficacy and mechanism.

\section{ACKNOWLEDGEMENTS}

We thank the patient for participating in the study.

Funding. Sponsorship for this study and Rapid Service Fee were funded by grants from the Special fund for Key talents training of Zhejiang Province (No:[2017]102); Clinical training project of middle-age famous TCM doctor of Zhejiang Province (No:[2017]22); National Natural Science Foundation of China (grant no. 81503645) and Natural Science Foundation of Zhejiang Province $(\mathrm{CN})$ (grant no. Q20H270078).

Authorship. All named authors meet the International Committee of Medical Journal Editors (ICMJE) criteria for authorship for this article, take responsibility for the integrity of the work as a whole, and have given their approval for this version to be published.

Authorship Contributions. Hongfang Tian and Hantong $\mathrm{Hu}$ contributed equally to this work.

Disclosures. Hongfang Tian, Hantong $\mathrm{Hu}$, Xingling Li, Jing Liu, Qin Guo, Yang Li, and Dexiong Han have nothing to disclose.

Compliance with Ethics Guidelines. Written informed consent was obtained from the patient for publication of this case report and any accompanying images. Institutional review board approval was not required for a case report.

Data Availability. Data sharing is not applicable to this article as no datasets were generated or analyzed during the current study.

Open Access. This article is licensed under a Creative Commons Attribution-NonCommercial 4.0 International License, which permits any non-commercial use, sharing, adaptation, distribution and reproduction in any medium or format, as long as you give appropriate credit to the original author(s) and the source, provide a link to the Creative Commons licence, and indicate if changes were made. The images or other third party material in this article are included in the article's Creative Commons licence, unless indicated otherwise in a credit line to the material. If material is not included in the article's Creative Commons licence and your intended use is not permitted by statutory regulation or exceeds the permitted use, you will need to obtain permission directly from the copyright holder. To view a copy of this licence, visit http://creativecommons.org/licenses/by$\mathrm{nc} / 4.0 /$.

\section{REFERENCES}

1. Li H, Li Y, Guo Z, Hao L, Li Y, Tang Y, Guo Y, Zhang D, He L, Wang Y, Meng Y, Li F, Ni J. Low-temperature plasma radiofrequency ablation in phantom limb pain: a case report. Brain Circ. 2018;4(2):62-4.

2. Aldington D, Small C, Edwards D, Ralph J, Woods P, Jagdish S, Moore RA. A survey of post-amputation pains in serving military personnel. J R Army Med Corps. 2014;160(1):38-41.

3. Ephraim PL, Wegener ST, MacKenzie EJ, Dillingham TR, Pezzin LE. Phantom pain, residual limb pain, and back pain in amputees: results of a national survey. Arch Phys Med Rehabil. 2005;86(10): 1910-9.

4. Kuffler DP. Coping with phantom limb pain. Mol Neurobiol. 2018;55(1):70-84.

5. Sinha R, van den Heuvel WJ, Arokiasamy P. Factors affecting quality of life in lower limb amputees. Prosthet Orthot Int. 2011;35(1):90-6. 
6. Briand MM, Boudier-Réveret M, Rodrigue X, Sirois G, Chang MC. A moving residual limb: botulinum toxin to the rescue. Transl Neurosci. 2020;29(11): 34-7.

7. Carlen PL, Wall PD, Nadvorna H, Steinbach T. Phantom limbs and related phenomena in recent traumatic amputations. Neurology. 1978;28(3): 211-7.

8. Aternali A, Katz J. Recent advances in understanding and managing phantom limb pain. F1000Res. 2019;8:1167.

9. Duarte D, Bauer CCC, Pinto CB, Saleh Velez FG, Estudillo-Guerra MA, Pacheco-Barrios K, Gunduz ME, Crandell D, Merabet L, Fregni F. Cortical plasticity in phantom limb pain: a fMRI study on the neural correlates of behavioral clinical manifestations. Psychiatry Res Neuroimaging. 2020;30(304): 111151.

10. Attal N, Cruccu G, Baron R, Haanpää M, Hansson P, Jensen TS, Nurmikko T. EFNS guidelines on the pharmacological treatment of neuropathic pain: 2010 revision. Eur J Neurol. 2010;17(9):1113-e88.

11. Robinson LR, Czerniecki JM, Ehde DM, Edwards WT, Judish DA, Goldberg ML, Campbell KM, Smith DG, Jensen MP. Trial of amitriptyline for relief of pain in amputees: results of a randomized controlled study. Arch Phys Med Rehabil. 2004;85(1): $1-6$.

12. Wilder-Smith $\mathrm{CH}$, Hill LT, Laurent S. Postamputation pain and sensory changes in treatment-naive patients: characteristics and responses to treatment with tramadol, amitriptyline, and placebo. Anesthesiology. 2005;103(3):619-28.

13. Hanley MA, Ehde DM, Campbell KM, Osborn B, Smith DG. Self-reported treatments used for lowerlimb phantom pain: descriptive findings. Arch Phys Med Rehabil. 2006;87(2):270-7.

14. Eichenberger U, Neff F, Sveticic G, Björgo S, Petersen-Felix S, Arendt-Nielsen L, Curatolo M. Chronic phantom limb pain: the effects of calcitonin, ketamine, and their combination on pain and sensory thresholds. Anesth Analg. 2008;106(4):1265-73 (table of contents).

15. Flor H. Maladaptive plasticity, memory for pain and phantom limb pain: review and suggestions for new therapies. Expert Rev Neurother. 2008;8(5):809-18.

16. Bowen JB, Wee CE, Kalik J, Valerio IL. Targeted muscle reinnervation to improve pain, prosthetic tolerance, and bioprosthetic outcomes in the amputee. Adv Wound Care (New Rochelle). 2017;6(8):261-7.
17. McNamara CT, Iorio ML. Targeted muscle reinnervation: outcomes in treating chronic pain secondary to extremity amputation and phantom limb syndrome. J Reconstr Microsurg. 2020;36(4): 235-40.

18. Prologo JD, Gilliland CA, Miller M, Harkey $\mathrm{P}$, Knight J, Kies D, Hawkins CM, Corn D, Monson DK, Edalat F, Dariushnia S, Brewster L. Percutaneous image-guided cryoablation for the treatment of phantom limb pain in amputees: a pilot study. J Vasc Interv Radiol. 2017;28(1):24-34.e4.

19. Kaur A, Guan Y. Phantom limb pain: a literature review. Chin J Traumatol. 2018;21(6):366-8.

20. Ramachandran VS, Rogers-Ramachandran D. Synaesthesia in phantom limbs induced with mirrors. Proc Biol Sci. 1996;263(1369):377-86.

21. Chan BL, Witt R, Charrow AP, Magee A, Howard R, Pasquina PF, Heilman KM, Tsao JW. Mirror therapy for phantom limb pain. $N$ Engl $J$ Med. 2007;357(21):2206-7.

22. Li J, Li T, Li G, Liu H, Zhang X. Selective nerve root injection of ozone for the treatment of phantom limb pain: three case reports. Medicine (Baltimore). 2020;99(16):e19819.

23. Rostaminejad A, Behnammoghadam M, Rostaminejad M, Behnammoghadam Z, Bashti S. Efficacy of eye movement desensitization and reprocessing on the phantom limb pain of patients with amputations within a 24-month follow-up. Int J Rehabil Res. 2017;40(3):209-14.

24. Hu X, Trevelyan E, Yang G, Lee MS, Lorenc A, Liu J, et al. The effectiveness of acupuncture or TENS for phantom limb syndrome. II: a narrative review of case studies. Eur J Integr Med. 2014;6(3):365-81.

25. Davies A. Acupuncture treatment of phantom limb pain and phantom limb sensation in a primary care setting. Acupunct Med. 2013;31(1):101-4.

26. Tseng CC, Chen PY, Lee YC. Successful treatment of phantom limb pain and phantom limb sensation in the traumatic amputee using scalp acupuncture. Acupunct Med. 2014;32(4):356-8.

27. Kurath-Koller S, Bauchinger S, Sperl D, Leithner A, Urlesberger B, Raith W. Use of NADA ear acupuncture in an adolescent patient with phantom limb pain after surgery for osteosarcoma. Acupunct Med. 2015;33(1):82-4.

28. Lee IS, Jung WM, Lee YS, Wallraven C, Chae Y. Brain responses to acupuncture stimulation in the prosthetic hand of an amputee patient. Acupunct Med. 2015;33(5):420-4. 
29. Jankovic J. Peripherally induced movement disorders. Neurol Clin. 2009;27:821-32.

30. Devor M, Rappaport ZH. Pain and the pathophysiology of damaged nerve. In: Fields $\mathrm{H}$, editor. Pain syndromes in neurology. London: Butterworths; 1990. p. 47-83.

31. Marion MH, Gledhill RF, Thompson PD. Pain and the pathophysiology of damaged nerve. Mov Disord. $1989 ; 4(4): 354-8$.

32. Kulisevsky J, Martí-Fàbregas J, Grau JM. Spasms of amputation stumps. J Neurol Neurosurg Psychiatry. 1992;55(7):626-7.

33. Seidel S, Kechvar-Parast J, Sycha T, Zeitlhofer J. The first case of a "jumping stump" syndrome in a lower limb amputee responding to pramipexole. Eur J Neurol. 2011;18(4):e45-6.

34. Dave SJ, Salyer J, Desai KA. Botulinum toxin type A for the treatment of postamputation residual limb myokymia: a case report. PM R. 2010;2(8):777-9.

35. Kern U, Martin C, Scheicher S, Müller H. Effects of botulinum toxin type B on stump pain and involuntary movements of the stump. Am J Phys Med Rehabil. 2004;83(5):396-9.

36. Ozbek SE, Zarifoglu M, Karli N. A case of involuntary spasm movements in amputation stump. Int J Med Med Sci. 2013;3:361-2.

37. Elavarasi A, Goyal V. Jumping stump: look before you label. BMJ Case Rep. 2019;12(4):e228249.

38. Buntragulpoontawee M, Pattamapaspong N, Tongprasert S. Multiple neuromas cause painful "jumping stump" in a transfemoral amputee: a case report. Int J Low Extrem Wounds. 2016;15(3): 271-3.

39. Iacono RP, Linford J, Tourian A, Sandyk R. Baclofen in the treatment of post-amputation autonomous stump movements. Eur Neurol. 1987;26(3):141-4.

40. Oleson T. Auriculotherapy manual: Chinese and Western systems of ear acupuncture. 4th ed. Edinburgh: Churchill Livingstone Elsevier; 2013.

41. Yeh $\mathrm{CH}$, Huang L. Comprehensive and systematic auricular diagnosis protocol. Med Acupunct. 2013;25(6):423-36.
42. Kligler B, Nielsen A, Kohrherr C, Schmid T, Waltermaurer E, Perez E, Merrell W. Acupuncture therapy in a group setting for chronic pain. Pain Med. 2018;19(2):393-403.

43. Jan AL, Aldridge ES, Rogers IR, Visser EJ, Bulsara MK, Niemtzow RC. Does ear acupuncture have a role for pain relief in the emergency setting? A systematic review and meta-analysis. Med Acupunct. $2017 ; 29(5): 276-89$.

44. Tsai SL, Fox LM, Murakami M, Tsung JW. Auricular acupuncture in emergency department treatment of acute pain. Ann Emerg Med. 2016;68(5):583-5.

45. Zhong Q, Wang D, Bai YM, Du SZ, Song YL, Zhu J. Effectiveness of auricular acupressure for acute postoperative pain after surgery: a systematic review and meta-analysis. Chin J Integr Med. 2019;25(3):225-32.

46. Moura CC, Chaves ECL, Cardoso ACLR, Nogueira DA, Azevedo C, Chianca TCM. Auricular acupuncture for chronic back pain in adults: a systematic review and metanalysis. Rev Esc Enferm USP. 2019;19(53):e03461.

47. Ye XX, Gao YZ, Xu ZB, Liu QX, Zhan CJ. Effectiveness of perioperative auricular therapy on postoperative pain after total hip arthroplasty: a systematic review and meta-analysis of randomised controlled trials. Evid Based Complement Alternat Med. 2019;3(2019):2979780.

48. You E, Kim D, Harris R, D'Alonzo K. Effects of auricular acupressure on pain management: a systematic review. Pain Manag Nurs. 2019;20(1): $17-24$.

49. Cha NH, Sok SR. Effects of auricular acupressure therapy on primary dysmenorrhea for female high school students in South Korea. J Nurs Scholarsh. 2016;48(5):508-16.

50. Oleson T. Neurophysiological basis of auricular acupuncture. In: Clinical acupuncture. Berlin, Heidelberg: Springer; 2001. p. 97-112.

51. Alimi D, Geissmann A, Gardeur D. Auricular acupuncture stimulation measured on functional magnetic resonance imaging. Med Acupunct. 2002;13:18-21. 